\title{
"Forecasting stock returns on the Amman Stock Exchange: Do neural networks outperform linear regressions?"
}

\begin{tabular}{|c|c|}
\hline AUTHORS & $\begin{array}{l}\text { Abdel Razzaq Al Rababa'a } \\
\text { Zaid Saidat (iD } \\
\text { Raed Hendawi (D) }\end{array}$ \\
\hline ARTICLE INFO & $\begin{array}{l}\text { Abdel Razzaq Al Rababa'a, Zaid Saidat and Raed Hendawi (2021). Forecasting } \\
\text { stock returns on the Amman Stock Exchange: Do neural networks outperform } \\
\text { linear regressions?. Investment Management and Financial Innovations, 18(4), } \\
\text { 280-296. doi:10.21511/imfi.18(4).2021.24 }\end{array}$ \\
\hline DOI & http://dx.doi.org/10.21511/imfi.18(4).2021.24 \\
\hline RELEASED ON & Wednesday, 01 December 2021 \\
\hline RECEIVED ON & Friday, 24 September 2021 \\
\hline \multirow[t]{2}{*}{ ACCEPTED ON } & Tuesday, 09 November 2021 \\
\hline & $(\mathrm{cc})$ EY \\
\hline LICENSE & $\begin{array}{l}\text { This work is licensed under a Creative Commons Attribution } 4.0 \text { International } \\
\text { License }\end{array}$ \\
\hline JOURNAL & "Investment Management and Financial Innovations" \\
\hline ISSN PRINT & $1810-4967$ \\
\hline ISSN ONLINE & $1812-9358$ \\
\hline PUBLISHER & LLC "Consulting Publishing Company "Business Perspectives" \\
\hline FOUNDER & LLC "Consulting Publishing Company "Business Perspectives" \\
\hline
\end{tabular}

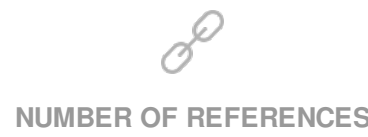

55
NUMBER OF FIGURES

5
NUMBER OF TABLES

5

(C) The author(s) 2021. This publication is an open access article. 


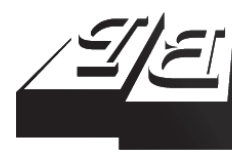

\section{BUSINESS PERSPECTIVES}

LLC "CPC "Business Perspectives" Hryhorii Skovoroda lane, 10, Sumy, 40022, Ukraine www.businessperspectives.org
Received on: $24^{\text {th }}$ of September, 2021 Accepted on: $9^{\text {th }}$ of November, 2021 Published on: $1^{\text {st }}$ of December, 2021

(c) Abdel Razzaq Al Rababảa, Zaid Saidat, Raed Hendawi, 2021

Abdel Razzaq Al Rababa’a, Assistant Professor of Banking and Finance, Faculty of Economics and Administrative Sciences, Yarmouk University, Jordan.

Zaid Saidat, Assistant Professor Faculty of Business, Department of Finance and Banking Sciences, Applied Science Private University, Jordan. (Corresponding author)

Raed Hendawi, Assistant Professor of Finance, Faculty of Economics and Administrative Sciences, Yarmouk University, Jordan. REGRESSIONS?

\begin{abstract}
Different models have been used in the finance literature to predict the stock market returns. However, it remains an open question whether non-linear models can outperform linear models while providing accurate predictions for future returns. This study examines the prediction of the non-linear artificial neural network (ANN) models against the baseline linear regression models. This study aims specifically to compare the prediction performance of regression models with different specifications and static and dynamic ANN models. Thus, the analysis was conducted on a growing market, namely the Amman Stock Exchange. The results show that the trading volume and interest rates on loans tend to explain the monthly returns the most, compared to other predictors in the regressions. Moreover, incorporating more variables is not found to help in explaining the fluctuations in the stock market returns. More importantly, using the root mean square error (RMSE), as well as the mean absolute error statistical measures, the static ANN becomes the most preferred model for forecasting. The associated forecasting errors from these metrics become equal to 0.0021 and 0.0005 , respectively. Lastly, the analysis conducted with the dynamic ANN model produced the highest RMSE value of 0.0067 since November 2018 following the amendment to the Jordanian income tax law. The same observation is also seen since the emerging of the COVID-19 outbreak $($ RMSE $=0.0042)$.
\end{abstract}

\section{Keywords predicting stock returns, artificial neural networks, linear models, COVID-19}

JEL Classification C45, C53, D53, G12

\section{INTRODUCTION}

The Amman Stock Exchange (hereafter ASE) is one of the fast-growing and frontiers markets in the Middle East ${ }^{1}$. Specifically, the value of shares purchased by non-Jordanians in June 2021 became equal to JD 19.4 million compared to the value of JD 5.1 million being reported a year later (ASE, 2021). This sharp increase in the number of foreign ownership in the market requires careful consideration for the non-linear models. That is, doing so can maximize the profit out of trading in the market. However, the ASE overall index witnessed sharp declines in recent years following the global financial crisis and the amendments made to the Jordanian tax law in 2018. Consequently, in recent years the Jordanian government starts using more comprehensive policies in the capital market to improve the private sector. These policies also aim to change the regulations of the capital market and make them more consistent with international standards (AlShiab, 2006; ASE, 2020). These policies, in turn, are expected to enhance the investment in the ASE.

1 The most recent report by Morgan Stanley Capital International (MSCI) classified the Jordanian stock market as a frontier market along with the Bahraini and Omani markets from the Middle East. 
Nevertheless, predicting stock performance represents one of the main challenges for people interested in investing in the stock markets. This issue even arises in the ASE as one of the most liquid and volatile markets in the Arabian region. That is, the stock market has features such as discontinuity and volatile multi-faceted elements because many elements have influence, such as general economic attitudes, political activities, and assumptions of the brokers (Hadavandi et al., 2010). Observing the excess volatility in the ASE, the ability to make quick decisions is necessary for success, and it is very important that transactions take place in the smallest investment horizon (Barakat et al., 2016). Moreover, the importance of making the more accurate prediction in the stock market stems from the fact that the stock market itself is the source of economic activities, which can be a highly advantageous place for investors with possibilities to grow their capital and wealth.

On the one hand, several stock traders and economic analysts have studied historical patterns of financial time series data and suggested different methods for forecasting stock performance. Examples of these methods include linear regressions. Yet, these approaches suffer from several problems including the common home bias (Siemsen et al., 2010). On the other hand, machine learning models, such as Artificial Neural Networks (ANNs) are generally considered black-box statistical models whose specifications are automatically derived from the way that computation is executed by the brain. However, their elements allow them to be appropriate for any dataset at hand. That is, ANNs can generate the forecasts out of any kind of data while depending on a number of hidden layers and not allowing for direct intervention by the final user. Thereby, this results in more accuracy in making predictions for the future and allows for the non-linearity pattern to be investigated between a set of variables. Additionally, it was argued that the ANNs can deal with the outliers in the dataset coinciding with the demonetization events and the COVID-19 pandemic (Chandrika \& Srinivasan, 2021)

So far, research concerning the prediction of the ASE returns has been limited to using traditional linear models (Al-Shiab, 2006). Other studies also employ qualitative data to demonstrate the applicability of the ANNs in forecasting the prices in the ASE (Hammad et al., 2007). However, such a comparison between the predictability of the basic linear models and non-linear ANNs in the Jordanian stock market is still required. Doing that is expected to benefit the investors in the ASE since it provides them with more information on the accuracy of prediction.

\section{LITERATURE REVIEW}

Artificial Neural Network (ANN) is one of the most commonly used methods in forecasting. Empirically, several studies have been conducted to examine the predictability of the NNs model against other traditional linear approaches in stock markets. Among these, for instance, Donaldson and Kamstra (1996) demonstrated the superiority of the ANNs over the traditional linear models in forecasting volatility in four developed stock markets. Similarly, Qi and Maddala (1999) found that the $\mathrm{NN}$ method outperforms linear forecasts and naive model forecasts. However, they prove that when considering the transaction costs, it is only the case that the switching portfolio constructed based on the linear forecasts outperforms the NN model. This finding is further enhanced by Qi (1999) since it was found that the forecast of ANN is not stable over time. Using data for thirty-three emerging markets over the sample period from 1992 to 1997, Harvey et al. (2000) found that neural networks outperform the linear regression model and the buy-and-hold strategy. In forecasting all the shares return in the FT all share index and the Dow Jones Industrial Average, Kanas (2001) found that the ANNs are more accurate than the linear regression in the forecasting exercise. Chen et al. (2003) found that ANN provides more accurate forecasts for the Taiwan stock market relative to the Kalman filter and random walk approaches.

Cao et al. (2005) found that the univariate and multivariate NNs are better compared to the Fama and French's models in forecasting the Shanghai stock market. Their finding is, however, found to differ across the firms in the sample. 
In another study, Pérez-Rodríguez et al. (2005) found that that ANNs perform better in forecasting than the random walk model. However, this evidence is found to be weak and to exist when the linear AR and the smooth transition autoregressive models are used later on for some forecast horizons. A study by Dropsy (1996) found the surprising result that the superiority of the ANNs is not significant relative to the other linear models. Furthermore, Desai and Bharati (1998) found that neural networks provide more accurate forecasts than linear regressions only for large stocks and corporate debt instruments. For the small stocks, however, this evidence is found to be insignificant. While predicting Istanbul Stock Exchange indexes, Emin (2009) found that ANNs perform better than the buy-and-hold approach. Yet, a new contradictory result regarding the superiority of the ANN is also reached by Al-Zubi et al. (2010), since they found that the predictive power for stock returns on the ASE has not significantly improved using the ANNs. Moreover, forecasting the movements in the NASDAQ stock market, Guresen et al. (2011) found that classical NN model multilayers (ML) outperform dynamic artificial NN and GARCH-ML with only a little difference. Bing et al. (2012) also found striking results regarding the inability of the backpropagation network to provide prediction in the Shanghai Stock Exchange market. That is, the ANN is found unable to forecast the short-term return.

Prior studies have also revealed that both linear regression and NNs can be used effectively for producing predictions in different environments. That has been specifically done while employing more complicated modeling approaches (Matsumura et al., 2015; Adisa et el., 2019; Piekutowska et al., 2021). Ahangar et al. (2010) used neural network regression to predict stock prices. In their study, ten macro-economic variables and thirty financial variables were considered for a general regression neural network with three layers. Of these variables, both financial and economic predictors are employed to estimate the stock price through the Components Analysis (ICA). It was found that the neural network approach is better than linear regressions. Other studies have also examined the predictability of the ANNs for the noisy intraday returns. Guresen et al. (2011) studied the performance of multilayer cognition (MLP), dynamic
ANN models, and hybrid ANN models in predicting market performance. Wang et al. (2011) proved that introducing the conditional heteroscedasticity structure into the ANNs can make their predictions more accurate relative to the linear models.

Kara et al. (2011) uncover more accuracy in the predictability of the ANN relative to the support vector machine approach. Fadlalla and Amani (2014) found that ANNs provide more efficient forecasts for the Qatari Stock Exchange index. That result has been found after comparing the performance of the neural networks with the moving average autoregressive model. For example, Matias and Reboredo (2012) found that ANNs outperform the random walk linear models but they are not able to clearly outperforms other non-linear models. In another study, Sukhia et al. (2014) performed the forecasting using linear regression, simple moving average algorithms, and backpropagation. The study concluded that the BP performed slightly better than linear regressions. Khashei and Hajirahimi (2017) uncovered more accurate predictions from the combined ARIMAMultilayer perceptron neural networks model for Chinese and American stock market data. Using a portfolio construction framework, Yildiz and Yildiz (2020) found that portfolios constructed with the dynamic NNs provide greater annualized returns relative to those used in the baseline methods.

Comparing the forecasting performance of several types of NNs has been also considered in other studies. For instance, Wu and Duan (2017) found that the predictability of the BP and Elman neural networks tends to differ for projecting the price trends in the Chinese stock market 300 Index. A study by Hiransha et al. (2018) also observed that not all the ANNs can provide equal forecasts in the Indian and New York Stock Exchanges. They found that the convolutional ANN is the best model compared to the competing models.

In trying to produce more accurate forecasts, Zhang et al. (2018) employed the random forest approach to predict the changes in the Chinese exchange market. After doing so, the study became able to categorize the stock prices into four categories depending on the end of the day closing 
prices The outcome of the study is found to benefit the trading behavior. More recently, a study by Selvamuthu et al. (2019) evaluates the forecasting performance of several properties of ANN for the tick return data in the Bombay stock market. They finally found that the predictability tends to vary over the tick horizon and not to be ideal for one property in all the forecasting scenarios. Using data from the Indian stock market, Sahoo and Mohanty (2020) proved that the hybrid models incorporating the ANN provide better forecasting performance than the individual neural network. More recently, Katris and Kavussanos (2021) found that ANN, along with other machine learning models, clearly provides comparable performance relative to a set of models belonging to the autoregressive moving average modeling approach.

To sum up, reviewing the related literature provides mixed results regarding the predictability of the ANNs. That is, the superiority of the ANNs over other linear models depends on the market itself, the ANN specification, and the competing models. More specifically, studies conducted in the ASE are very few and provide contradictory findings (Al-Zubi et al., 2010).

\section{AIMS}

The objectives of this paper are as follows. First, it compares the predictability of different specifications of the ANNs and the linear regression models in a growing Arabian market, namely the ASE. Second, it examines whether incorporating more variables in the linear regressions improves the forecasting performance of these models. Lastly, it evaluates the predictability over an extended sample period to cover the impact of the COVID-19 pandemic.

\section{HYPOTHESES AND METHODOLOGY}

\subsection{Research hypotheses}

The mixed evidence in literature triggers the need for examining the following hypotheses:
H1: ANNs models provide more accurate forecasts for the stock returns in the ASE than the linear regressions.

H2: The dynamic neural network provides more accurate predictions than the static neural network.

H3: Incorporating more predictors in the regression helps in improving the prediction by the linear regressions.

H4: The predictability of the dynamic NN tends to diminish during the COVID-19 period.

\subsection{Baseline linear regression models}

The main estimation approach in this study assumes that selected economic variables convey important information for the stock returns. To examine this further, five main linear regression models have been estimated as follows:

$$
\begin{aligned}
& \operatorname{Ret}_{t}=\alpha+\sum_{S V=1}^{n} \beta_{1} S V_{t}+e_{t} . \\
& \operatorname{Ret}_{t}=\alpha+\sum_{S V=1}^{n} \beta_{1} S V_{t}+\sum_{I R=1}^{n} \beta_{2} I R_{t}+e_{t} .
\end{aligned}
$$

$\operatorname{Ret}_{t}=\alpha+\sum_{S V=1}^{n} \beta_{1} S V_{t}+\sum_{I R=1}^{n} \beta_{2} I R_{t}+$

$+\sum_{P F=1}^{n} \beta_{3} P F_{t}+e_{t}$.

$\operatorname{Ret}_{t}=\alpha+\sum_{S V=1}^{n} \beta_{1} S V_{t}+\sum_{I R=1}^{n} \beta_{2} I R_{t}+$

$+\sum_{P F=1}^{n} \beta_{3} P F_{t}+\sum_{T B=1}^{n} \beta_{4} T B_{t}+e_{t}$

$\operatorname{Ret}_{t}=\alpha+\sum_{S V=1}^{n} \beta_{1} S V_{t}+\sum_{I R=1}^{n} \beta_{2} I R_{t}+$

$+\sum_{P F=1}^{n} \beta_{3} P F_{t}+\sum_{T B=1}^{n} \beta_{4} T B_{t}+\sum_{M B=1}^{n} \beta_{5} M B_{t}+e_{t}$.

Model (Equation) 1 examines the possible significant impact of the stock market variables. Models $2,3,4$, and 5 investigate the incremental effects originating from IR, $\mathrm{PF}, \mathrm{TB}$, and $\mathrm{MB}$ variables re- 


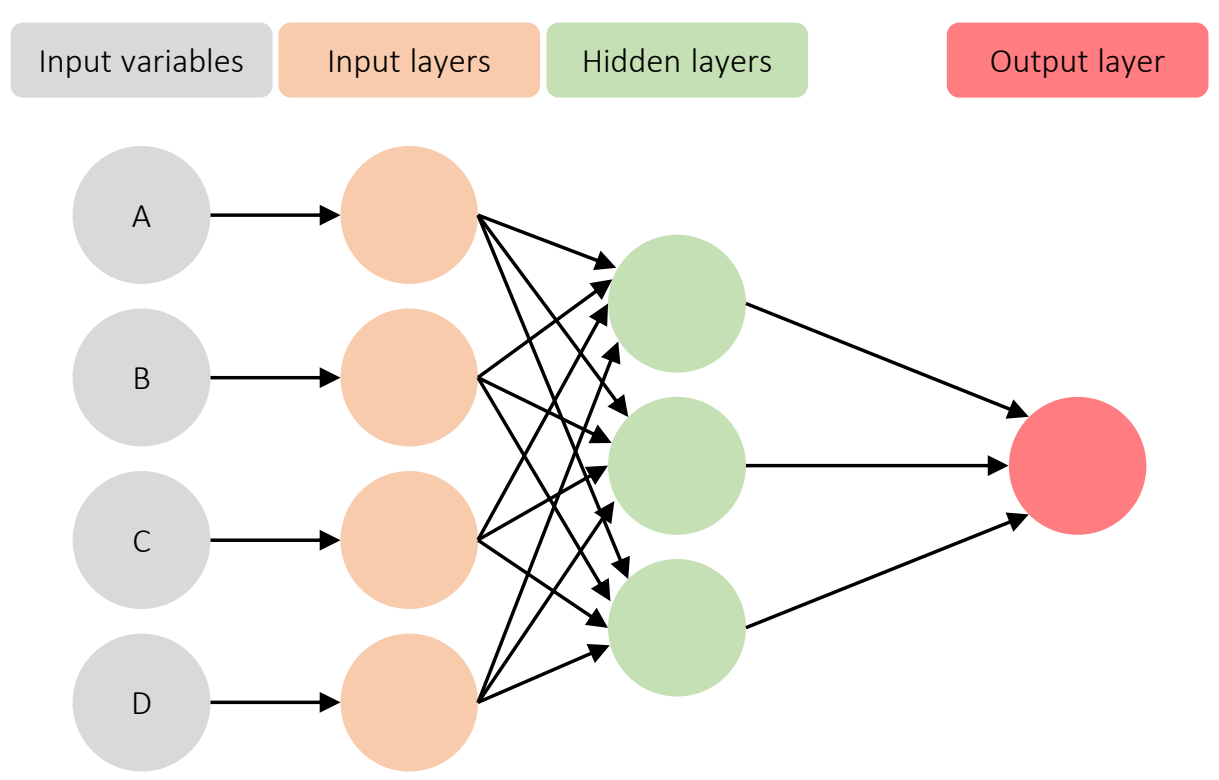

Notes: The circles in the middle represent nodes in the network.

Figure 1. Basic design of the artificial neural network

spectively. In Model 6, the possible serial correlation in the return series was controlled by adding the one lag of the returns as a new independent variable. The predictors are described further.

$$
\begin{aligned}
& \text { Ret }_{t}=\alpha+\sum_{S V=1}^{n} \beta_{1} S V_{t}+\sum_{I R=1}^{n} \beta_{2} I R_{t}+ \\
& +\sum_{P F=1}^{n} \beta_{3} P F_{t}+\sum_{T B=1}^{n} \beta_{4} T B_{t}+ \\
& +\sum_{M B=1}^{n} \beta_{5} M B_{t}+\beta_{6} R E T_{t-1}+e_{t} .
\end{aligned}
$$

\subsection{Artificial neural networks}

The neural networks are employed to forecast the stock market returns. The ANN is mainly used for discharging forecasting following initial training using a feed-ahead approach from each neural level to the other one. After that, the outcome associated with the output level is in contrast with its corresponding labeled values. In the next step, the model components can be adjusted based on the comparison between the output results and their target counterparts. Following this stage, better performance for the ANN can be attained ${ }^{2}$. For further detail, the network structure is given in
Figure $1^{3}$. The nodes of the input layer are set to the predictors, and the output layer produces the projected return series. To speed up the exercise process, this study employs a random search approach. This method is an improvement on the grid search technique as it optimizes the parameters within a shorter time.

\subsubsection{Static backpropagation in the ANN}

Backpropagation (BP) is a special category of the ANN that employs interrelated layers and hidden parts. The approach aims to reduce the degree of the non-linear complexity in the system by allowing for a certain number of hidden layers existing in the system. Besides, the BP approach utilizes the deepest descent learning method to ensure the simplicity of uncovering the relationship between the input and output variables in the system.

On the other hand, the ANN requires the employment of two unobserved layers when the data at hand is not reliable enough for validating the stage. A level filter is essential for the input data (Mao et al., 2021). Practically, the learning stage in the BP applies to the connections within the system allowing the hidden units to absorb all the characters of the input variables. However, it re-

2 The description of the ANN is made short and one can refer to Mackay (1996) to know the main components of the ANN.

3 For a detailed description of the training algorithm, see Schalkoff (1997). 


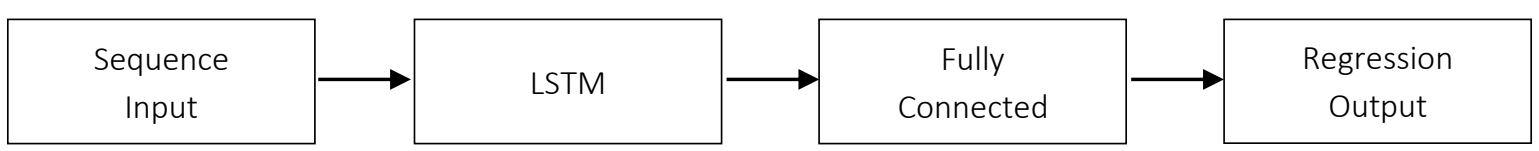

Figure 2. Simple LSTM design

mains difficult to understand the reasons behind generating specific outputs from the system.

\subsubsection{Dynamic LSTM}

LSTM network is a specific form of neural network that helps in understanding historical data and sequential information problems and thereby avoid some of the limitations of traditional ANNs that tend to form long-term interlinkages, as shown in Figure 2. The network design inserts LSTM layer after the sequence input layer, followed by a fully linked layer, a softmax layer, and an arrangement output layer, in order to predict specific tags (Mao et al., 2021).

The purpose of the LSTM layer is to keep the release of the network at a specific time step, which can be transported with minor modifications, but which can be influenced by new data. Furthermore, the Tanh activation function exerts a non-linear activation transformation on the information within the ANN structure ${ }^{4}$.

\subsubsection{Forecasting evaluation}

To assess the forecast, the most common statistical measures were used, namely the root mean square error (RMSE) and the mean absolute error (MAE), such as:

$$
\begin{aligned}
& R M S E=\sqrt{\tau^{-1} \sum_{t=T_{1}}^{\tau}\left(\hat{r e t_{t}}-r e t_{t}\right)} . \\
& M A E=\tau^{-1} \sum_{t=T_{1}}^{\tau}\left|\hat{r e t_{t}}-r e t_{t}\right| .
\end{aligned}
$$

where $\tau$ is the number of observations in the out-

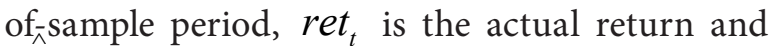
ret $_{t}$ is the forecasted return series from the corresponding model. The RMSE assigns more weight to large forecast errors against small forecast er- rors, while the $M A E$ is more robust to the possible existence of noisy return observations. Following the logic in the forecasting literature, the full sample was divided into $30 \%$ (70\%) in (out of) sample where the later period has been considered for the prediction exercise. Henceforth, the forecasting period spans from June 2017 to the end of the sample period.

The main concern was to examine whether any of the NNs either with static or dynamic specifications can beat the benchmark linear regressions models. For the latter, Model 6 was specifically considered since it incorporates all the predictors in the study at one times.

\section{DATA}

This paper used monthly closing prices for the ASE whole market index as well as economic datasets for the period from January 2011 to February 2020. The decision for starting and end dates is restricted by the availability of the economic data in the Central Bank of Jordan. However, the closing price series is available for a longer period. To begin, the stock price series was retrieved from the ASE's website and converted to returns by applying the usual log difference approach (i.e. Ret $=$ Log (diff (price)) at any time period. The same was done to the economic series excluding the interest rate data, where the corresponding data are left as they are without transformation.

Table 1 describes and categorizes the independent variables being used in the study into 5 groups: the stock market; interest rate; public finance; money and banking; and trade balance factors. These predictors have been selected based on the findings in the relevant literature. For example, Ma et al. (2021) found that trading volume data can predict stock market returns.

4 The function considers any real value as input and outputs values in the range from -1 to 1.

5 A set of regressions was also performed with the separate predictors' group being inserted one-by-one into each regression. That, however, produced qualitatively and quantitatively similar findings to those reported here. 
Chen et al. (2003) found evidence for the role of the public finance factors. Another recent study by Kammoun et al. (2021) found evidence for the stock market reactions to project finance loans. Their findings, for example, indicate the importance of money and banking variables in predicting the stock market returns. More specifically, $\mathrm{Lu}$ et al. (2021) found that bank loans convey important information for investors in the Chinese stock market particularly when the target companies perform good corporate governance practices. Lastly, Li et al. (2020) indicated that trade frictions between China and the US (as an indicator for the power of trade balance) affect the Chinese stock market performance.
Table 2 describes the main statistics in the variables of the study. Overall, these preliminary results indicate that the mean is mostly negative for stock market variables while it tends to be positive and even higher when either the money and banking or the public finance variables are considered. Furthermore, performing the Jacque-Bera test confirms the rejection of the normality assumption in all variables except those belonging to the trade balance and internal and external public debt. The correlation coefficient values between the stock returns and the predictors are reported in Table 3. There is evidence of a significant correlation between the stock market variables and return. The same is also true when the WIR, MB2, and MB9 are considered.

Table 1. List of predictors in the regressions and static NN

\begin{tabular}{|c|c|c|}
\hline$\#$ & Variable & Notation \\
\hline \multicolumn{3}{|c|}{ Panel A: Stock market variables } \\
\hline 1 & High price & $\mathrm{HIGH}$ \\
\hline 2 & Low price & LOW \\
\hline 3 & Open price & OPEN \\
\hline 4 & LN (Trading volume (No. of shares)) & VOL \\
\hline \multicolumn{3}{|c|}{ Panel B: Interest rate variables } \\
\hline 5 & Interbank rates & INTER \\
\hline 6 & Weighted interest rates on loans & WIR \\
\hline \multicolumn{3}{|c|}{ Panel C: Public finance variables (JD millions) } \\
\hline 7 & Tax expenses & PF1 \\
\hline 8 & Gross expenses & PF2 \\
\hline 9 & Internal public debt & PF3 \\
\hline 10 & External Public debt & PF4 \\
\hline \multicolumn{3}{|c|}{ Panel D: Money and bank variables } \\
\hline 11 & Money supply 2 & MB1 \\
\hline 12 & Total banks assets & MB2 \\
\hline 13 & Net debt on private sector & MB3 \\
\hline 14 & Net debt on public sector & MB4 \\
\hline 15 & Gross credit facilities granted by banks & MB5 \\
\hline 16 & Total deposit in banks & MB6 \\
\hline 17 & Total deposits by non-banking companies & MB7 \\
\hline 18 & Loans to the agricultural industry & MB8 \\
\hline 19 & Loans to the mining industry & MB9 \\
\hline 20 & Loans to the industrial sector & MB10 \\
\hline 21 & Loans for the free trade purposes & MB11 \\
\hline 22 & Loans to the construction sector & MB12 \\
\hline 23 & Loans to the transportation services & MB13 \\
\hline 24 & Loans to hotels and hospitality industry & MB14 \\
\hline 25 & Loans to the public utility & MB15 \\
\hline 26 & Loans for the financial service & MB16 \\
\hline 27 & Loans for other activities & MB17 \\
\hline 28 & Direct Credit facilities granted by banks & MB18 \\
\hline 29 & Direct Credit facilities for buying stocks only & MB19 \\
\hline \multicolumn{3}{|c|}{ Panel E: Trade balance variables } \\
\hline 30 & Exports of goods and services & EXP \\
\hline 31 & Imports of goods and services & $\mathrm{IMP}$ \\
\hline
\end{tabular}

Note: The economic data is collected from the Central Bank of Jordan. 
Table 2. Descriptive statistics

\begin{tabular}{|c|c|c|c|c|c|c|c|c|c|}
\hline & \multicolumn{5}{|c|}{ Panel A: Stock market variables } & \multicolumn{2}{|c|}{$\begin{array}{c}\text { Panel B: } \\
\text { Interest rate } \\
\text { variables }\end{array}$} & \multicolumn{2}{|c|}{$\begin{array}{c}\text { Panel C: } \\
\text { Export and import } \\
\text { variables }\end{array}$} \\
\hline & RET & VOL & OPEN & HIGH & LOW & WIR & INTER & IMP* & EXP* \\
\hline Mean & $-5.58 \mathrm{E}-05$ & -0.00069 & -0.00069 & -0.00065 & -0.00282 & -0.000943 & 0.004166 & $-7.85 E-05$ & 0.000732 \\
\hline Median & $-2.92 \mathrm{E}-05$ & -0.00066 & -0.00038 & -0.00117 & -0.00419 & -0.00112 & 0 & -0.01372 & 0.003623 \\
\hline Maximum & 0.004331 & 0.0146 & 0.018241 & 0.020104 & 0.0887 & 0.037364 & 0.205563 & 0.389409 & 0.298496 \\
\hline Minimum & -0.00566 & -0.03133 & -0.03409 & -0.02271 & -0.06706 & -0.053425 & -0.26504 & -0.29692 & -0.31922 \\
\hline Std. Dev. & 0.001445 & 0.006162 & 0.006425 & 0.005675 & 0.024371 & 0.012891 & 0.063754 & 0.12532 & 0.13119 \\
\hline Skewness & -0.63297 & -1.07873 & -1.09564 & 0.124092 & 0.600811 & -0.767176 & 0.010118 & 0.248525 & -0.09512 \\
\hline Kurtosis & 6.606077 & 7.763109 & 9.171736 & 5.529756 & 5.008992 & 7.185757 & 6.935973 & 2.913096 & 2.805946 \\
\hline \multicolumn{10}{|c|}{ Panel D: Money and banking variables } \\
\hline & MB1 & MB2 & MB3 & MB4 & MB5 & MB6 & MB7 & MB8 & MB9 \\
\hline Mean & 0.004055 & -0.00313 & 0.005572 & 0.007519 & 0.00579 & 0.003834 & 0.005941 & 0.004173 & 0.005768 \\
\hline Median & 0.004247 & -0.0108 & 0.005459 & 0.011033 & 0.005376 & 0.004384 & 0.005053 & 0.003418 & 0.006947 \\
\hline Maximum & 0.019833 & 0.129169 & 0.021351 & 0.067187 & 0.025628 & 0.031697 & 0.343708 & 0.166416 & 0.431564 \\
\hline Minimum & -0.0227 & -0.07703 & -0.01506 & -0.07593 & -0.02046 & -0.06025 & -0.20262 & -0.18333 & -0.39151 \\
\hline Std. Dev. & 0.007293 & 0.042304 & 0.005098 & 0.026377 & 0.005989 & 0.010584 & 0.082111 & 0.047993 & 0.100193 \\
\hline Skewness & -0.48871 & 1.389612 & -0.3584 & -0.88933 & -0.22782 & -1.81522 & 0.471329 & 0.084162 & -0.0518 \\
\hline \multirow[t]{2}{*}{ Kurtosis } & 4.911316 & 4.888284 & 5.09767 & 4.6868 & 7.014342 & 14.24915 & 5.210625 & 6.565997 & 7.968722 \\
\hline & MB10 & MB11 & MB12 & MB13 & MB14 & MB15 & MB16 & MB17 & MB18 \\
\hline Mean & 0.005527 & 0.001366 & 0.00737 & -0.00312 & 0.003256 & 0.01272 & 0.004418 & 0.00638 & 0.00579 \\
\hline Median & 0.007654 & 0.002513 & 0.005143 & 0.001057 & 0.00563 & 0.004963 & 0.009787 & 0.006439 & 0.005376 \\
\hline Maximum & 0.074694 & 0.0601 & 0.056354 & 0.206219 & 0.119128 & 0.162873 & 0.184442 & 0.067558 & 0.025634 \\
\hline Minimum & -0.12167 & -0.11921 & -0.02895 & -0.67313 & -0.10762 & -0.06345 & -0.30741 & -0.06026 & -0.02046 \\
\hline Std. Dev. & 0.031554 & 0.021675 & 0.013106 & 0.072256 & 0.027541 & 0.038585 & 0.058325 & 0.020726 & 0.006008 \\
\hline Skewness & -0.83499 & -1.41716 & 1.072555 & -7.10309 & -0.35744 & 1.584573 & -1.35729 & -0.0964 & -0.21776 \\
\hline Kurtosis & 5.608577 & 10.61334 & 5.837507 & 69.22944 & 8.520197 & 6.42888 & 11.8853 & 4.684131 & 6.960228 \\
\hline
\end{tabular}

Panel E: Public finance variables

\begin{tabular}{|c|c|c|c|c|c|}
\hline Mean & MB19 & PF1* & PF2 & PF3* & PF4 \\
\hline Median & -0.00602 & 0.000361 & 0.008781 & 0.007489 & 0.008946 \\
\hline Maximum & -0.00123 & -0.00223 & 0.019287 & 0.007567 & 0.001262 \\
\hline Minimum & 0.30881 & 0.901519 & 0.63422 & 0.048649 & 0.157871 \\
\hline Std. Dev. & -0.30601 & -0.84377 & -1.1096 & -0.0273 & -0.04087 \\
\hline Skewness & 0.094656 & 0.343164 & 0.289566 & 0.014406 & 0.02763 \\
\hline Kurtosis & 0.253495 & 0.132178 & -0.98644 & -0.05684 & 2.721686 \\
\hline
\end{tabular}


Table 3. Pairwise correlation

\begin{tabular}{|c|c|c|c|}
\hline & Return & & Return \\
\hline \multirow{2}{*}{ VOL } & 0.38494 & \multirow{2}{*}{ MB8 } & -0.03017 \\
\hline & {$[0]$} & & [0.7543] \\
\hline \multirow{2}{*}{ OPEN } & 0.32806 & \multirow{2}{*}{ MB9 } & -0.22349 \\
\hline & {$[0.0005]$} & & [0.0189] \\
\hline \multirow{2}{*}{$\mathrm{HIGH}$} & 0.32703 & \multirow{2}{*}{ MB10 } & -0.02637 \\
\hline & [0.0005] & & [0.7845] \\
\hline \multirow{2}{*}{ LOW } & 0.20579 & \multirow{2}{*}{ MB11 } & 0.034012 \\
\hline & {$[0.0310]$} & & [0.7243] \\
\hline \multirow{2}{*}{ WIR } & 0.20034 & \multirow{2}{*}{ MB12 } & 0.015368 \\
\hline & [0.0359] & & [0.8734] \\
\hline \multirow{2}{*}{ INTER } & -0.06622 & \multirow{2}{*}{ MB13 } & 0.008048 \\
\hline & [0.4919] & & [0.9335] \\
\hline \multirow{2}{*}{ IMP } & 0.05952 & \multirow{2}{*}{ MB14 } & -0.00836 \\
\hline & [0.5367] & & [0.9309] \\
\hline \multirow{2}{*}{ EXP } & 0.0622 & \multirow{2}{*}{ MB15 } & -0.03506 \\
\hline & [0.5186] & & {$[0.7161]$} \\
\hline \multirow{2}{*}{ MB1 } & 0.08571 & \multirow{2}{*}{ MB16 } & 0.093515 \\
\hline & {$[0.3733]$} & & {$[0.3312]$} \\
\hline \multirow{2}{*}{ MB2 } & 0.188938 & \multirow{2}{*}{ MB17 } & -0.03177 \\
\hline & {$[0.0481]$} & & [0.7418] \\
\hline \multirow{2}{*}{ MB3 } & -0.03386 & \multirow{2}{*}{ MB18 } & -0.04658 \\
\hline & {$[0.7255]$} & & {$[0.6289]$} \\
\hline \multirow{2}{*}{ MB4 } & -0.089 & \multirow{2}{*}{ MB19 } & 0.093635 \\
\hline & {$[0.3552]$} & & [0.3306] \\
\hline \multirow{2}{*}{ MB5 } & -0.04653 & \multirow{2}{*}{ PF1 } & 0.01796 \\
\hline & [0.6293] & & [0.8523] \\
\hline \multirow{2}{*}{ MB6 } & -0.04277 & \multirow{2}{*}{ PF2 } & 0.021672 \\
\hline & {$[0.6573]$} & & {$[0.8222]$} \\
\hline \multirow{2}{*}{ MB7 } & 0.087808 & \multirow{2}{*}{ PF3 } & -0.01001 \\
\hline & {$[0.3617]$} & & [0.9174] \\
\hline
\end{tabular}

Note: Numbers in brackets denote the P-values.

\section{RESULTS AND DISCUSSION}

\subsection{Baseline analysis}

Table 4 reports the results from the baseline linear regression models with different specifications. To begin with, the estimates from Model 1 indicate that none of the prices proxies statistically affects the current stock market returns. Yet, the trading information data offers a clear significant prediction for the returns. This result seems to complement the previous findings in the literature for the role of trading volume in predicting the stock return reversal (Ülkü \& Onishchenko, 2019) and the stock return autocorrelation (Campbell et al., 1993). This observation holds when other specifications have been estimated in the subsequent analyses, indicating that the trading volume remains a valid predictor for the current stock mar- ket return. That is, its impact cannot be encompassed by any other predictor. Theoretically, the importance of trading in formulating the returns in ASE can also support the argument of Karpoff (1986) that investors in the market might tend to trade even in the absence of new information. In other words, it might be the case that the speculative desires for the investors in ASE are that they trigger the need for trading regardless of the size of information being available in the market. This, in turn, can motive investors to buy more stocks and subsequently increase prices

Adding the interest rate variables to Model 2 provides new results. Specifically, WIR conveys significant information for explaining the stock market returns. This evidence tends to exist at the $1 \%$ significance level. The related coefficient value is positive indicating that higher interest rates on loans maximize the stock market returns. This, however, contradicts the previous findings of Alam and Uddin (2009) who found evidence for the negative relationship between the changes in the stock market prices and interest rates in a sample of developing and developed countries. This contrarian finding can be attributed to the prevailing trading behavior in ASE, where margin trading does fully exist. To say it differently, investors in the market rely more on their savings before starting their investment in the market. With the increase in the proportion of foreign investment in the market, investors use their own cash, which is accumulated before investing in the Jordanian market. This makes the variations in the local interest rates less important to the existing investors in the market. Considering the interest rate variables again reveals that the INTER negatively though only economically explains the stock market return. This new result holds in all models again. This finding proves the opposite relationship between the overnight cost of borrowing between banks and stock market returns.

On the other hand, adding the public finance variables uncovers cross-sectional differences in the results between the four PF variables. Using any of the models again (from Model 3 to 6) shows a negative simultaneous relationship between the tax expenses (PF1) and stock market returns. This observation means more taxes induce less trading and stock market returns accordingly. Overall, es- 
timating Model 4 with the PF variables reduces the Adj. $\mathrm{R}^{2}$ to 0.1094 relative to the highest previous level of 0.1550 when Model 2 is considered. Turning the attention to Model 5 reveals a different story. The overall explanation of the model has been sharply reduced and the Adj. $\mathrm{R}^{2}$ reached the lowest value of 0.0435 . It can also be observed that, regardless of the large number of variables being used at this stage, only loans to the mining industry measured by MB9 significantly explain the current returns. This evidence is, however, very small at a $10 \%$ significance level. Henceforth, estimating Model 5 proves the importance of looking at the number of loans at the disaggregated level rather than the total loan amount being given in a specific year.

Lastly, controlling for the series correlation in stock market returns results in the highest Adj. $\mathrm{R}^{2}$ relative to the counterpart estimates in all the previous models. After estimating the model, the significance of the MB9 has disappeared. Conversely, more direct credit facilities for buying stocks appear now to positively and significantly drive stock market returns at the $1 \%$ significance level.

Overall, the results in Table 4 indicate that trading volume and WIR explains the stock market return in ASE more than any variables. To emphasize, adding more variables does not make a big difference in the overall performance of the baseline model. Therefore, the paper concerns whether the degree of linearity in the estimation itself plays a major role in the forecasting stage. Doing that should help investors in the ASE to get an accurate forecast and formulate their trading strategies accordingly to maximize the capital gain out of their investments. Thus, the paper reports the results and offers a comparison between the performance of the baseline models and the ANN models in an out-of-sample (forecasting) exercise.

\subsection{Forecast performance}

Table 5 reports the estimates from the out-ofsample analysis. For one step-ahead both the RMSE and MAE forecasting assessment criteria select the static $\mathrm{NN}$ against the other competing models. According to these metrics, the model produces the lowest forecasting error values of 0.0012 and 0.0005 respectively. However, LSTM appears to yield the largest RMSE relative to other models. On the contrary, this model along with specifications 3 and 4 produces the lowest errors according to the MAE approach.

Overall, the model that incorporates more predictors does not seem to provide more accurate forecasts relative to its counterparts. In other words, it is the non-linearity that matters the most in providing the most accurate prediction for the Jordanian stock market return. This result holds at the selected forecasting horizon of one month to coincide with the frequency of the monthly predictors being used in the analysis. Adopting the non-linear static NN approach will then help the short-term investors in ASE in getting precise forecasts while trading in the market.

Generally, the superiority of the static NN over the other benchmark models is in line with the previous finding in the forecasting literature, for example, include Pérez-Rodríguez et al. (2005) and Katris and Kavussanos (2021). Yet, the evidence from this study is generated in an emerging and fast-growing Arab market. It is also reached after using comprehensive predictors in the estimation process. Lastly, the performance of various specifications of the NN was examined.

\subsection{LSTM approach to graphical analyses}

Figures 3 and 4 show the dynamic forecasts and the related RMSE from the LSTM respectively. Noticeably, the forecasted return remains close to the actual over the full sample period with only a few exceptions. These periods are specifically from November 2018 (following the amendment to the Jordanian income tax law) and from December 2019 in the aftermath of the COVID-19 period (Figure 3). Such findings suggest that caution should be used as LSTM may not be suitable at all-time such as when the market is affected by shocks in the Jordanian economy. Figure 4 confirms this by the sudden jump in the RMSE in November 2018 and December 2020.

Overall, the empirical results confirm the acceptance of the first hypothesis while rejecting the second and the third hypotheses. 
Table 4. Estimates from the baseline models

\begin{tabular}{|c|c|c|c|c|c|c|}
\hline Variable & Model 1 & Model 2 & Model 3 & Model 4 & Model 5 & Model 6 \\
\hline \multirow{2}{*}{ Constant } & $-4.22 E-06$ & $1.49 E-05$ & $-4.00 E-05$ & $-4.62 E-05$ & 0.000209 & 0.000191 \\
\hline & $(-0.06092)$ & $(0.196935)$ & $(-0.308940)$ & $(-0.341028)$ & $(1.057025)$ & $(0.882866)$ \\
\hline \multirow{2}{*}{$\mathrm{HIGH}$} & 0.123922 & 0.126185 & 0.121834 & 0.126087 & 0.139106 & 0.055087 \\
\hline & $(1.007147)$ & $(1.042489)$ & $(0.976987)$ & $(0.971982)$ & $(0.885792)$ & $(0.369446)$ \\
\hline \multirow{2}{*}{ LOW } & -0.024680 & -0.02566 & -0.025741 & -0.026286 & -0.032142 & -0.010320 \\
\hline & $(-1.021667)$ & $(-1.129892)$ & $(-1.122856)$ & $(-1.111196)$ & $(-1.174309)$ & $(-0.458136)$ \\
\hline \multirow{2}{*}{ OPEN } & 0.009108 & 0.004372 & -0.002201 & 0.003141 & 0.022171 & -0.011347 \\
\hline & $(0.094313)$ & $(0.047550)$ & $(-0.022603)$ & $(0.031036)$ & $(0.188584)$ & $(-0.129270)$ \\
\hline \multirow{2}{*}{ VOL } & $0.049434^{* * *}$ & $0.050798^{* * *}$ & $0.058828^{* * *}$ & $0.050871^{* * *}$ & $0.030578 * * *$ & $0.074875^{* * *}$ \\
\hline & $(2.476799)$ & $(2.481390)$ & $(2.519673)$ & $(2.426190)$ & $(2.218665)$ & $(2.618449)$ \\
\hline \multirow{2}{*}{ INTER } & & -0.00088 & -0.001025 & -0.001042 & -0.000613 & -0.001011 \\
\hline & & $(-0.603020)$ & $(-0.622273)$ & $(0.618457)$ & $(-0.270689)$ & $(0.539623)$ \\
\hline \multirow{2}{*}{ WIR } & & $0.020296 * * *$ & $0.020673^{* * *}$ & $0.020882 * * *$ & $0.023855^{* * *}$ & $0.021178 * * *$ \\
\hline & & $(2.917919)$ & $(2.747415)$ & $(2.718929)$ & $(2.880794)$ & $(2.617452)$ \\
\hline \multirow{2}{*}{ PF1 } & & & $-4.56 \mathrm{E}-05$ & $-5.85 E-05$ & -0.000288 & -0.000228 \\
\hline & & & $(-0.100408)$ & $(-0.133143)$ & $(-0.653062)$ & $(-0.656847)$ \\
\hline \multirow{2}{*}{ PF2 } & & & 0.000146 & $1.22 \mathrm{E}-05$ & -0.000318 & -0.000177 \\
\hline & & & $(0.497469)$ & $(0.033928)$ & $(-0.570611)$ & $(-0.401365)$ \\
\hline \multirow{2}{*}{ PF3 } & & & 0.003789 & 0.004620 & 0.009216 & 0.006813 \\
\hline & & & $(0.398448)$ & $(0.470670)$ & $(0.660963)$ & $(0.639521)$ \\
\hline \multirow{2}{*}{ PF4 } & & & 0.002708 & 0.002777 & 0.004922 & 0.005535 \\
\hline & & & $(0.497952)$ & $(0.487634)$ & $(0.714467)$ & $(0.848553)$ \\
\hline \multirow{2}{*}{ EXP } & & & & 0.000359 & 0.000378 & -0.000719 \\
\hline & & & & $(0.414066)$ & $(0.450362)$ & $(-0.718033)$ \\
\hline \multirow{2}{*}{ IMP } & & & & 0.000443 & 0.000755 & -0.000343 \\
\hline & & & & $(0.524298)$ & $(0.599080)$ & $(-0.345664)$ \\
\hline \multirow{2}{*}{ MB1 } & & & & & 0.009809 & 0.028220 \\
\hline & & & & & $(0.326507)$ & $(0.867434)$ \\
\hline \multirow{2}{*}{ MB2 } & & & & & 0.001800 & -0.007961 \\
\hline & & & & & $(0.318188)$ & $(-1.058869)$ \\
\hline & & & & & -0.012166 & -0.012338 \\
\hline MIB3 & & & & & $(-0.285322)$ & $(-0.353216)$ \\
\hline & & & & & -0.001891 & -0.006103 \\
\hline MB4 & & & & & $(-0.156162)$ & $(-516461)$ \\
\hline$M B{ }_{1}$ & & & & & -0.105523 & -0.214078 \\
\hline IVIBS & & & & & $(-0.148242)$ & $(-0.272570)$ \\
\hline$M A B$ & & & & & -0.013693 & -0.015709 \\
\hline MIB6 & & & & & $(0.904269)$ & $(-1.036372)$ \\
\hline & & & & & 0.002840 & 0.000236 \\
\hline MIB/ & & & & & $(1.273977)$ & $(0.106703)$ \\
\hline $\mathrm{MBR}$ & & & & & $8.23 \mathrm{E}-05$ & 0.000187 \\
\hline IVIB8 & & & & & $(0.024360)$ & $(0.088119)$ \\
\hline$M B O$ & & & & & $-0.002598^{*}$ & -0.001255 \\
\hline IVIBY & & & & & $(-1.765090)$ & $(-1.258772)$ \\
\hline & & & & & 0.005875 & -0.002347 \\
\hline MIBIO & & & & & $(0.295555)$ & $(-0.191286)$ \\
\hline MB11 & & & & & 0.01468 & 0.009526 \\
\hline IVIBII & & & & & $(0.578625)$ & $(0.575466)$ \\
\hline MB12 & & & & & 0.010853 & 0.001574 \\
\hline $\mathrm{M} B \mathrm{~B} \perp 2$ & & & & & $(0.383742)$ & $(0.074610)$ \\
\hline MB13 & & & & & 0.002701 & 0.001560 \\
\hline $\mathrm{M} \mid \mathrm{B} \perp 3$ & & & & & $(0.784191)$ & $(0.614295)$ \\
\hline & & & & & -0.002853 & 0.001759 \\
\hline MIB14 & & & & & $(-0.370534)$ & $(0.273915)$ \\
\hline MB15 & & & & & 0.006696 & 0.004534 \\
\hline IVIBIS & & & & & $(0.485752)$ & $(0.442136)$ \\
\hline & & & & & 0.003382 & 0.002582 \\
\hline IVIBI6 & & & & & $(0.944636)$ & $(1.006742)$ \\
\hline & & & & & 0.005120 & -0.004959 \\
\hline MB1/ & & & & & $(0.162989)$ & $(-0.222444)$ \\
\hline
\end{tabular}


Table 4 (cont.). Estimates from the baseline models

\begin{tabular}{|c|c|c|c|c|c|c|}
\hline Variable & Model 1 & Model 2 & Model 3 & Model 4 & Model 5 & Model 6 \\
\hline \multirow{2}{*}{ MB18 } & & & & & 0.026877 & 0.156481 \\
\hline & & & & & $(0.035133)$ & $(0.195787)$ \\
\hline \multirow{2}{*}{ MB19 } & & & & & 0.001317 & $0.004253^{* * *}$ \\
\hline & & & & & $(0.824597)$ & $(2.792863)$ \\
\hline \multirow{2}{*}{$\operatorname{Ret}(-1)$} & & & & & & $0.621843^{* * *}$ \\
\hline & & & & & & $(-5.536529)$ \\
\hline Adj. $R^{2}$ & 0.1362 & 0.1550 & 0.1248 & 0.1094 & 0.0435 & 0.3670 \\
\hline
\end{tabular}

Note: Numbers in brackets are the $t$-statistics. $* * *$ and $*$ denote the statistical significance at $1 \%$ and $10 \%$, respectively.

Table 5. Out-of-sample results (RMSE and MAE estimates)

\begin{tabular}{|c|c|c|}
\hline Model & RMSE & MAE \\
\hline Model 1 & 0.0015 & 0.0009 \\
\hline Model 2 & 0.0015 & 0.0009 \\
\hline Model 3 & 0.0014 & 0.0008 \\
\hline Model 4 & 0.0015 & 0.0008 \\
\hline Model 5 & 0.0013 & 0.0009 \\
\hline Model 6 & 0.0014 & 0.0009 \\
\hline Static NN & 0.0012 & 0.0005 \\
\hline LSTM & 0.0022 & 0.0008 \\
\hline
\end{tabular}

Note: Figure in bold indicates the model with the most forecasting accuracy according to the employed statistical proxy.

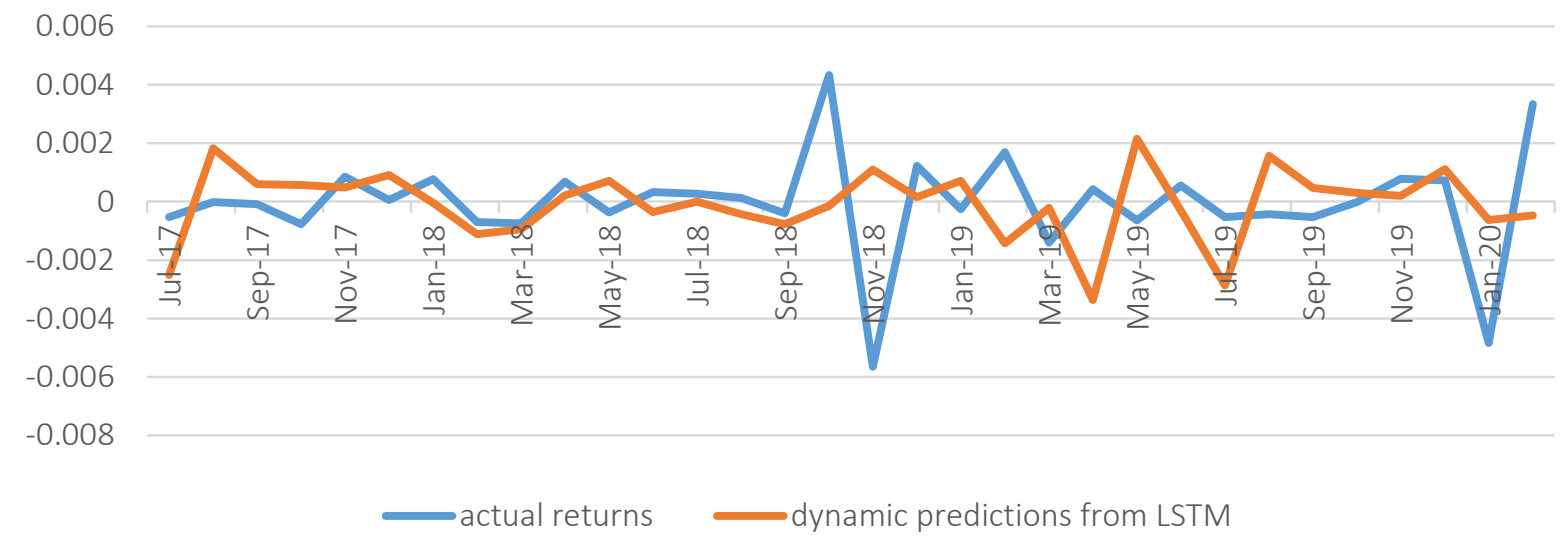

Figure 3. Dynamic forecasts from LSTM vs. actual returns

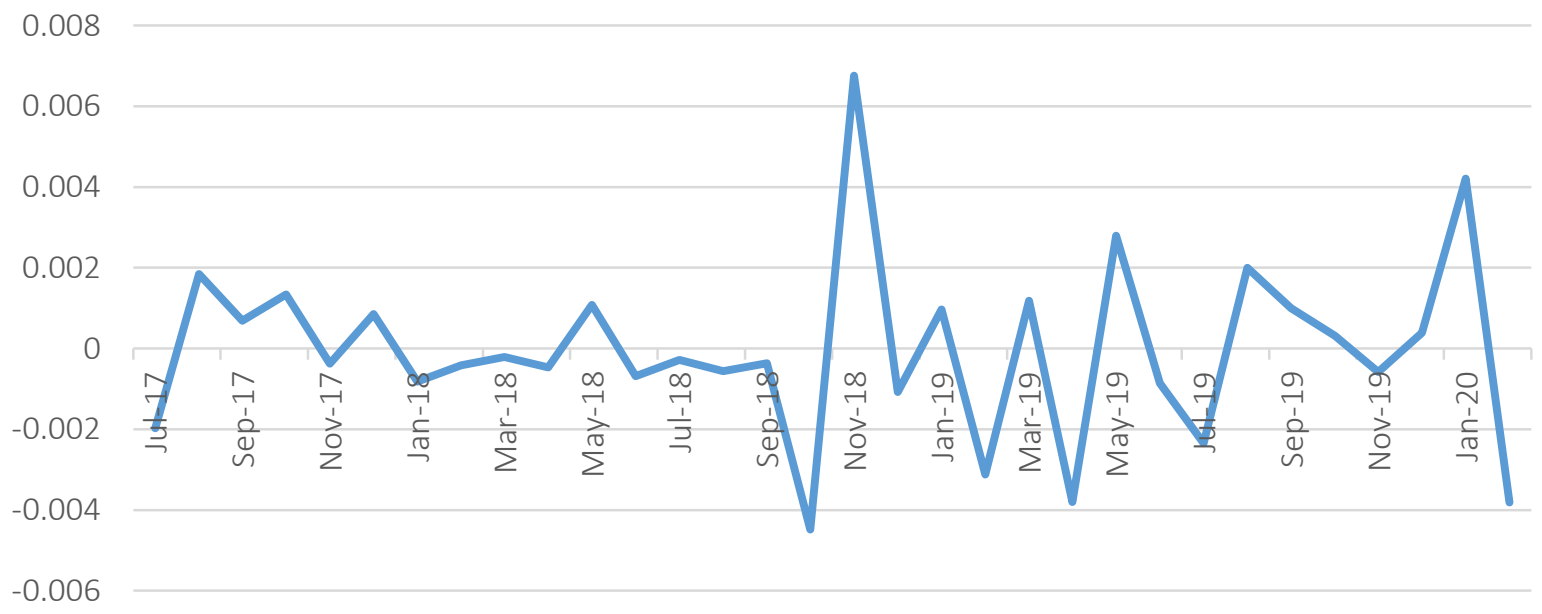

Figure 4. RMSE from the dynamic forecasts of LSTM 


\section{CONCLUSION}

This study examines the forecasting performance of neural network approaches against baseline linear regression models. Specifically, the ability of both static and long-short dynamic NNs in providing accurate one-month ahead forecast for the Amman Stock Exchange returns was investigated. To do so, monthly returns data over the period from January 2011 to February 2020 along with the stock market, public finance, trade balance, interest rate, and money and banking data, was used. The results highlighted that, firstly from the baseline analysis, both the trading volume and weighted average of the interest rates on loans tend to explain the monthly returns the most, regardless of the specification of the model being used in the analysis. Secondly, the model incorporating more var- iables does efficiently explain the current variations in the stock market return. Thirdly and most importantly, the forecasting exercise has resulted in a preference for the static NN more than any other competing model. Lastly, variations in the predictability of the LSTM over time were observed, meaning that the forecasting error of the LSTM is found to maximize at specific periods, such as following the amendment to the Jordanian income tax law as well as in the aftermath of the COVID-19 outbreak.

The results of this study bring important implications for investors in the ASE. Firstly, investors should not rely on baseline linear regression models to provide accurate forecasts for stock market returns. This study suggests that they should familiarize themselves with other non-linear techniques such as the static neural network. Lastly, there are some times in the market where the investments can be less stable and more complicated models are not so efficient at predictions. These include the dynamic LSTM as a pertinent example. In this case, investors are advised to carefully examine the macroeconomic level along with the stock market performance itself. Lastly, future research is encouraged to offer special training programs to investors in the stock market on how to use the black-box machine learning models such as the NNs. Further research can build on these findings by examining the performance of NN models on a sectoral level at different forecasting horizons. It can also examine the risk management implications of the results.

\section{AUTHOR CONTRIBUTIONS}

Conceptualization: Raed Hendawi.

Investigation: Zaid Saidat, Raed Hendawi.

Methodology: Abdel Razzaq Al Rababa’a.

Resources: Abdel Razzaq Al Rababa’a, Zaid Saidat.

Writing - original draft: Abdel Razzaq Al Rababa’a, Zaid Saidat, Raed Hendawi.

Writing - review \& editing: Abdel Razzaq Al Rababa’a, Zaid Saidat, Raed Hendawi.

\section{REFERENCES}

1. Adisa, O. M., Botai, J. O., Adeola, A. M., Hassen, A., Botai, C. M., Darkey, D., \& Tesfamariam, E. (2019). Application of artificial neural network for predicting maize production in South Africa. Sustainability, 11(4), 1145. https:// doi.org/10.3390/su11041145

2. Ahangar, R. G., Yahyazadehfar, M., \& Pournaghshband, H. (2010). The comparison of methods artificial neural network with linear regression using specific variables for prediction stock price in Tehran stock exchange. International Journal of Computer Science and Information Security, 7(2), 38-46. Retrieved from https://arxiv.org/ftp/arxiv/papers/1003/1003.1457.pdf

3. Alam, M. D., \& Uddin, G. (2009). Relationship between interest rate and stock price: empirical evidence from developed and developing countries.
International Journal of Business and Management, 4(3), 43-51. https://doi.org/10.5539/ijbm. v4n3p43

4. Al-Shiab, M. (2006). The predictability of the Amman stock exchange using the univariate autoregressive integrated moving average (ARIMA) model. Journal of Economic and Administrative Sciences, 22(2), 17-35. https://doi. org/10.1108/10264116200600006 
5. Al-Zubi, K. A., Salameh, H. M., \& Hamad, H. A. (2010). Does the Predicating Power of Stock Return in Amman Stock Exchange (ASE) Improved by Using the Artificial Neural Networks ANN? International Research Journal of Finance and Economics, 46, 80-97.

6. Amman Stock Exchange (ASE). (2020, August 25). The Amman Stock Exchange CEO: Launching Several Important Projects This Year In Accordance With The Latest International Standards And Practices. Retrieved from https://www.exchange.jo/en/news/ Amman-Stock-Exchange-CEOLaunching-several-important-projects-year-accordance-latest

7. Barakat, M. R., Elgazzar, S. H., \& Hanafy, K. M. (2016). Impact of macroeconomic variables on stock markets: Evidence from emerging markets. International Journal of Economics and Finance, 8(1), 195207. https://doi.org/10.5539/ijef. v8n1p195

8. Bing, Y., Hao, J. K., \& Zhang, S. C. (2012). Stock market prediction using artificial neural networks. Advanced Engineering Forum, 6(7).

9. Brooks, C., \& Tsolacos, S. (2003). International evidence on the predictability of returns to securitized real estate assets: econometric models versus neural networks. Journal of Property Research, 20(2), 133-155. https://doi. org/10.1080/0959991032000109517

10. Campbell, J. Y., Grossman, S. J., \& Wang, J. (1993). Trading volume and serial correlation in stock returns. The Quarterly Journal of Economics, 108(4), 905-939. Retrieved from https://scholar. harvard.edu/campbell/publications/ trading-volume-and-serial-correlation-stock-returns

11. Cao, Q., Leggio, K. B., \& Schniederjans, M. J. (2005). A comparison between Fama and French's model and artificial neural networks in predicting the Chinese stock market. Computers \& Operations Research 32(10), 2499-2512. https://doi. org/10.1016/j.cor.2004.03.015

12. Chandrika, P. V., \& Srinivasan, K. S. (2021). Predicting Stock Market Movements Using Artificial Neural Networks. Universal Journal of Accounting and Finance, 9(3), 405-410. http://doi.org/10.13189/ ujaf.2021.090315

13. Chen, A. S., Leung, M. T., \& Daouk, H. (2003). Application of neural networks to an emerging financial market: forecasting and trading the Taiwan Stock Index. Computers \& Operations Research, 30(6), 901-923. https://doi.org/10.1016/S03050548(02)00037-0

14. Connellan, O., \& James, H. (1998). Estimated realisation price (ERP) by neural networks: forecasting commercial property values. Journal of Property Valuation and Investment, 16(1), 71-86. https://doi. org/10.1108/14635789810205137

15. Desai, V. S., \& Bharati, R. (1998). The efficacy of neural networks in predicting returns on stock and bond indices. Decision Sciences, 29(2), 405-423. https:// doi.org/10.1111/j.1540-5915.1998. tb01582.x

16. Dropsy, V. (1996). Do macroeconomic factors help in predicting international equity risk premia? Testing the out-of-sample accuracy of linear and nonlinear forecasts. Journal of Applied Business Research, 12(3), 120-132.

17. Donaldson, R. G., \& Kamstra, M. (1996). Forecast combining with neural networks. Journal of Forecasting, 15(1), 49-61.

18. Emin, A. V. C. I. (2009). Stock return forecasts with artificial neural network models. Marmara Üniversitesi İktisadi ve İdari Bilimler Dergisi, 26(1), 443-461. Retrieved from https://dergipark.org.tr/en/ pub/muiibd/issue/485/4282

19. Fadlalla, A., \& Amani, F. (2014). Predicting next trading day closing price of Qatar exchange index using technical indicators and artificial neural networks. Intelligent Systems in Accounting, Finance and Management, 21(4), 209-223. http:// dx.doi.org/10.1002/isaf.1358

20. Guresen, E., Kayakutlu, G., \& Daim, T. U. (2011). Using artificial neural network models in stock market index prediction. Expert Systems with Applications, 38(8), 1038910397. https://doi.org/10.1016/j. eswa.2011.02.068
21. Hadavandi, E., Ghanbari, A., \& Abbasian-Naghneh, S. (2010). Developing an evolutionary neural network model for stock index forecasting. In D. S. Huang, M. McGinnity, L. Heutte, \& X. P. Zhang (Eds.), Advanced Intelligent Computing Theories and Applications. Communications in Computer and Information Science, 93 (pp. 407-415). Springer, Berlin, Heidelberg. http://dx.doi. org/10.1007/978-3-642-14831-6_54

22. Hammad, A. A. A., Ali, S. M. A., \& Hall, E. L. (2007). Forecasting the Jordanian stock price using artificial neural network. In C. H. Dagli (Ed.), Intelligent engineering systems through artificial neural networks. ASME Press. https://doi. org/10.1115/1.802655.paper42

23. Harvey, C. R., Travers, K. E., \& Costa, M. J. (2000). Forecasting emerging market returns using neural networks. Emerging Markets Quarterly, 4, 43-54. Retrieved from https://faculty.fuqua.duke. edu/ charvey/Teaching/CDROM_ BA456_2003/Other_Harvey_Papers/P61_Forecasting_emerging_market.pdf

24. Hiransha, M., Gopalakrishnan, E. A., Menon, V. K., \& Soman, K. P. (2018). NSE stock market prediction using deep-learning models. Procedia Computer Science, 132, 1351-1362. https://doi. org/10.1016/j.procs.2018.05.050

25. Hochreiter, S., \& Schmidhuber, J. (1997). Long short-term memory. Neural Computation, 9(8), 17351780. https://doi.org/10.1162/ neco.1997.9.8.1735

26. Kammoun, M., Power, G. J., \& Tandja, D. C. (2021). Capital market reactions to project finance loans. Finance Research Letters, 102115. https://doi.org/10.1016/j. frl.2021.102115

27. Kanas, A. (2001). Neural network linear forecasts for stock returns. International Journal of Finance \& Economics, 6(3), 245-254. https://doi. org/10.1002/ijfe.156

28. Kara, Y., Boyacioglu, M. A., \& Baykan, Ö. K. (2011). Predicting direction of stock price index movement using artificial neural networks and support vector 
machines: The sample of the Istanbul Stock Exchange. Expert Systems with Applications, 38(5), 5311-5319. https://doi.org/10.1016/j. eswa.2010.10.027

29. Karpoff, J. M. (1986). A theory of trading volume. The Journal of Finance, 41(5), 1069-1087. https:// doi.org/10.2307/2328164

30. Katris, C., \& Kavussanos, M. G. (2021). Time series forecasting methods for the Baltic dry index. Journal of Forecasting, 40(8), 15401565. https://doi.org/10.1002/ for. 2780

31. Khashei, M., \& Hajirahimi, Z. (2017). Performance evaluation of series and parallel strategies for financial time series forecasting. Financial Innovation, 3(1), 24. https://doi.org/10.1186/s40854-0170074-9

32. Kiani, K. M., \& Kastens, T. L. (2008). Testing forecast accuracy of foreign exchange rates: Predictions from feed forward and various recurrent neural network architectures. Computational Economics, 32, 383406. https://doi.org/10.1007/s10614008-9144-4

33. Li, Y., Zhuang, X., Wang, J., \& Zhang, W. (2020). Analysis of the impact of Sino-US trade friction on China's stock market based on complex networks. The North American Journal of Economics and Finance, 52, 101185. https://doi. org/10.1016/j.najef.2020.101185

34. Lu, L., Tumer-Alkan, G., Zhang, H., Xu, B., \& Wu, W. (2021). Do bank loans still convey information to investors? Evidence from the split share structure reform in China. Emerging Markets Review, 48, 100773. https://doi.org/10.1016/j. ememar.2020.100773

35. Ma, Y., Yang, B., \& Su, Y. (2021). Stock return predictability: Evidence from moving averages of trading volume. Pacific-Basin Finance Journal, 65, 101494. https://doi.org/10.1016/j.pacfin.2021.101494

36. MacKay, D. J. (1996). Hyperparameters: optimize, or integrate out? In Maximum entropy and bayesian methods (pp. 43-59). Springer. Retrieved from https:// bayes.wustl.edu/MacKay/alpha.pdf
37. Mao, G., Wang, M., Liu, J., Wang, Z., Wang, K., Meng, Y., Zhong, R., Wang, H., \& Li, Y. (2021). Comprehensive comparison of artificial neural networks and long short-term memory networks for rainfall-runoff simulation. Physics and Chemistry of the Earth, Parts A/B/C, 123, 103026. https://doi. org/10.1016/j.pce.2021.103026

38. Matias, J. M., \& Reboredo, J. C. (2012). Forecasting performance of nonlinear models for intraday stock returns. Journal of Forecasting, 31(2), 172-188. https://doi.org/10.1002/ for. 1218

39. Matsumura, K., Gaitan, C. F., Sugimoto, K., Cannon, A. J., \& Hsieh, W. W. (2015). Maize yield forecasting by linear regression and artificial neural networks in Jilin, China. The Journal of Agricultural Science, 153(3), 399-410. https://doi. org/10.1017/S0021859614000392

40. Moghaddam, A. H., Moghaddam, M. H., \& Esfandyari, M. (2016). Stock market index prediction using artificial neural network. Journal of Economics, Finance and Administrative Science, 21(41), 89-93. https://doi.org/10.1016/j. jefas.2016.07.002

41. Pérez-Rodríguez, J. V., Torra, S., \& Andrada-Félix, J. (2005). STAR and ANN models: forecasting performance on the Spanish "Ibex35 " stock index. Journal of Empirical Finance, 12(3), 490-509. Retrieved from https://ideas.repec.org/a/eee/ empfin/v12y2005i3p490-509.html

42. Piekutowska, M., Niedbała, G., Piskier, T., Lenartowicz, T., Pilarski, K., Wojciechowski, T., Pilarska, A. A., \& Czechowska-Kosacka, A. (2021). The Application of Multiple Linear Regression and Artificial Neural Network Models for Yield Prediction of Very Early Potato Cultivars before Harvest. Agronomy, 11(5), 885. https://doi.org/10.3390/ agronomy11050885

43. Preethi, G., \& Santhi, B. (2012). Stock market forecasting techniques: a survey. Journal of Theoretical \& Applied Information Technology, 46(1), 24-30. Retrieved from http://www.jatit.org/volumes/ Vol46No1/4Vol46No1.pdf

44. Qi, M. (1999). Nonlinear predictability of stock returns using financial and economic variables. Journal of Business \& Economic Statistics, 17(4), 419-429. https://doi. org/10.2307/1392399

45. Qi, M., \& Maddala, G. S. (1999). Economic factors and the stock market: a new perspective. Journal of Forecasting, 18(3), 151-166. https://doi.org/10.1002/(SICI)1099131X(199905)18:3\%3C151::AIDFOR716\%3E3.0.CO;2-V

46. Sahoo, S., \& Mohanty, M. N. (2020). Stock market price prediction employing artificial neural network optimized by gray wolf optimization. In S. Patnaik, A. Ip, M. Tavana, \& V. Jain (Eds.), New paradigm in decision science and management. Advances in Intelligent Systems and Computing, 1005 (pp. 77-87). Springer, Singapore. http://dx.doi. org/10.1007/978-981-13-9330-3_8

47. Schalkoff, R. J. (1997). Artificial neural networks. McGraw-Hill Higher Education.

48. Selvamuthu, D., Kumar, V., \& Mishra, A. (2019). Indian stock market prediction using artificial neural networks on tick data. Financial Innovation, 5(1), 16. http:// dx.doi.org/10.1186/s40854-0190131-7

49. Siemsen, E., Roth, A., \& Oliveira, P. (2010). Common method bias in regression models with linear, quadratic, and interaction effects. Organizational Research Methods, 13(3), 456-476.https://doi. org/10.1177/1094428109351241

50. Sukhia, K. N., Khan, A. A., \& Bano, M. (2014). Introducing Economic Order Quantity Model for inventory control in web based point of sale applications and comparative analysis of techniques for demand forecasting in inventory management. International Journal of Computer Applications, 107(19). https://doi.org/10.5120/18856-7385

51. Ülkü, N., \& Onishchenko, O. (2019). Trading volume and prediction of stock return reversals: Conditioning on investor types' trading. Journal of Forecasting, 38(6), 582-599. https:// doi.org/10.1002/for.2582

52. Wang, Z., Zeng, Y., Pan, H., \& Li, P. (2011). Predictability of moving average rules and nonlinear 
properties of stock returns:

Evidence from the China stock

market. New Mathematics and

Natural Computation, 7(02), 267279.

53. Wu, B., \& Duan, T. (2017). A performance comparison of neural networks in forecasting stock price trend. International Journal of Computational Intelligence Systems, 10(1), 336-346. http://dx.doi. org/10.2991/ijcis.2017.10.1.23

54. Yildiz, Z. \& Yildiz, S. B. (2020). A portfolio construction framework using LSTM-based stock markets forecasting. International Journal of Finance \& Economics. https://doi. org/10.1002/ijfe.2277

55. Zhang, J., Cui, S., Xu, Y., Li, Q., \& $\mathrm{Li}, \mathrm{T}$. (2018). A novel data-driven stock price trend prediction system. Expert Systems with Applications, 97, 60-69. https://doi.org/10.1016/j. eswa.2017.12.026

\section{APPENDIX A}
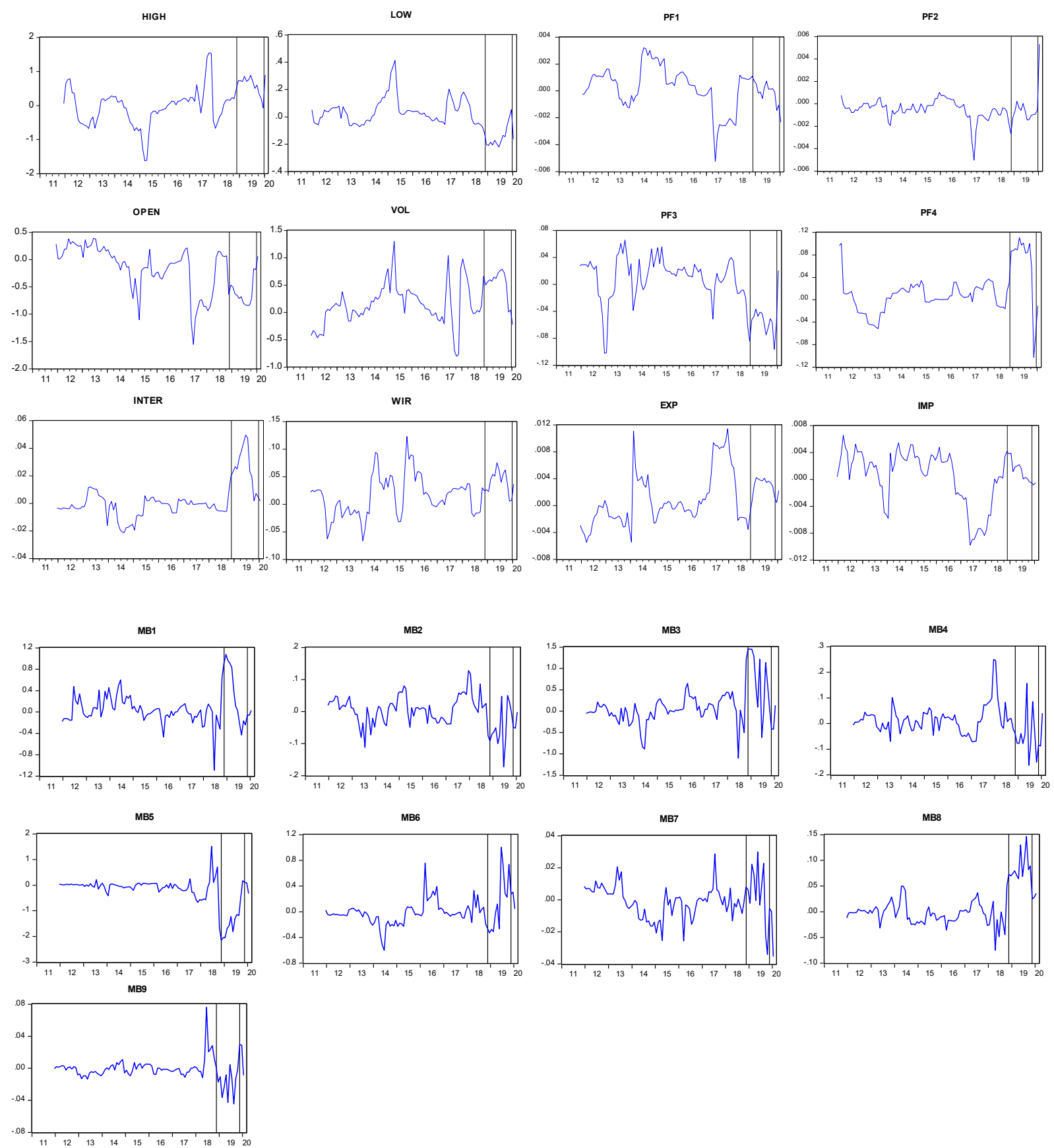

Note: Rolling regression estimates (with 12 months window size and one step ahead) after estimating Model 6. Shaded lines from left to right indicate the periods when the Jordanian tax law has been amended (November 2018) and the starting date of the COVID-19 outbreak (November 2019) respectively.

Figure A1. Rolling regression estimates from Model 6 

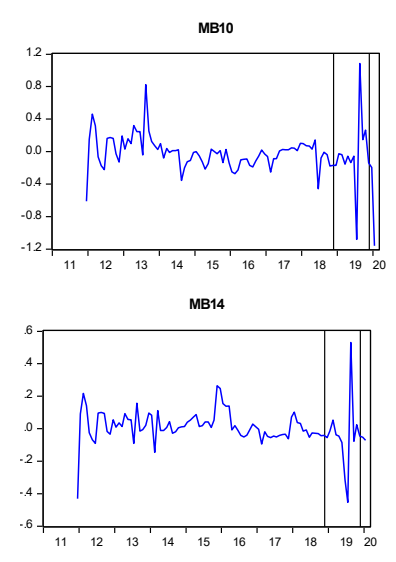

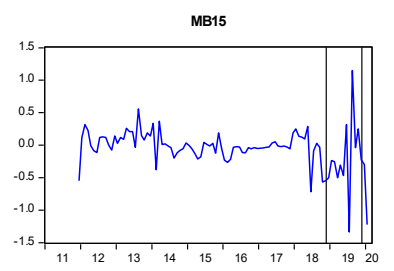

MB18

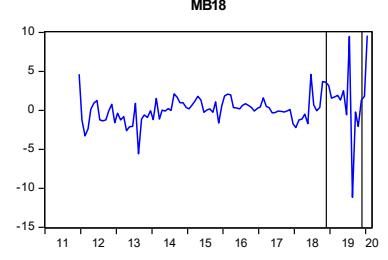

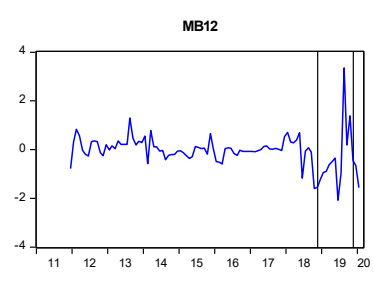

MB16
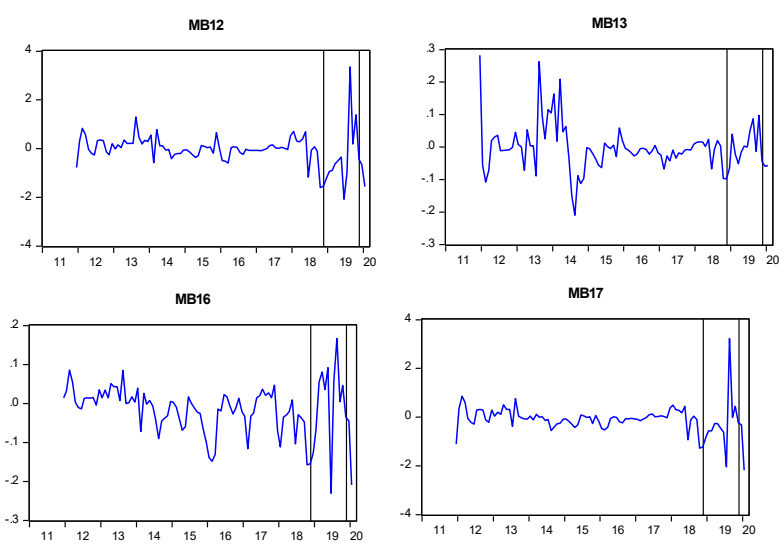

MB17

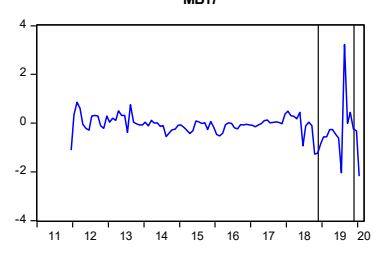

MB19

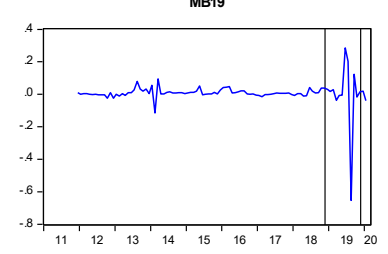

Figure A1 (cont.). Rolling regression estimates from Model 6 